\title{
Erratum: Stromal androgen receptor regulates the composition of the microenvironment to influence prostate cancer outcome
}

Damien A. Leach, Eleanor F. Need, Roxanne Toivanen, Andrew P. Trotta, Helen M. Palethorpe, David J. Tamblyn, Tina Kopsaftis, Georgina M. England, Eric Smith, Paul A. Drew, Carole B. Pinnock, Peng Lee, Jeff Holst, Gail P. Risbridger, Samarth Chopra, Donald B. DeFranco, Renea A. Taylor and Grant Buchanan

Oncotarget. 2015; 6:16135-16150

PMID: 25965833

The author name is incorrect.

Helen M. Palenthorpe

The corrected author name is provided here.

Helen M. Palethorpe 